\title{
О КИНЕТИЧЕСКИХ СВОЙСТВАХ ПРОСТАГЛАНДИН-ЭНДОПЕРОКСИД СИНТЕТАЗЫ
}

Простагландин (ПГ)-эндопероксид синтетаза, или диоксигеназа (К. Э. 1. 14. 99. 1), - первый в комплексе энзимов, осуществляющих превращение полиеновой жирной кислоты в стабильные ПГ и другие продукты $\left[{ }^{1}\right]$. Его кинетические свойства изучены еще недостаточно. В равной мере это относится и к самой диоксигеназе, состоящей, по всей вероятности, из двух энзимов $\left[{ }^{2}\right]$. Такое положение обусловлено в первую очередь трудностями выделения и очистки диоксигеназы $\left[{ }^{1,3}\right]$.

Характерными свойствами активированной фенолом диоксигеназы, выделенной из семенных пузырьков барана в виде ацетон-пентанового порошка, являются ее дальнейшая активация продуктом окисления в начальной стадии реакции и быстрая автокаталитическая инактивация $[4,5]$.

Задачи данного исследования - изучение кинетических свойств диоксигеназы в зависимости от состава реакционной среды, способа инициирования реакции, а также нахождение удобного метода расчета кинетических параметров по кривой поглощения кислорода.

\section{Результаты и их обсуждение}

Значение мономолекулярной константы инактивации $\left(k_{i}\right)$ ранее определялось по наклону прямой, полученной при обработке кинетической кривой поглощения кислорода в координатах «скорость поглощения $\left(v_{t}\right)$ - концентрация субстрата в данный момент времени $\left([S]_{t}\right) »\left[{ }^{4}\right]$. Получение прямой в указанных координатах соответствует случаю инактивации энзима в виде энзим-субстратного комплекса:

$$
E+S \stackrel{K_{s}}{\underset{\downarrow^{2}}{\rightleftarrows}} \underset{\substack{k_{l}=\alpha k_{2} \\ E_{i}}}{\stackrel{k_{2}}{\rightarrow}} E+P,
$$

где $E, S$ и $P-$ энзим, субстрат и продукт, соответственно;

$K_{s}$ - константа диссоциации фермент-субстратного комплекса;

$k_{2}$ - каталитическая константа.

Определение наклона по кривой - способ неудобный, поэтому, по нашему мнению, в данном случае целесообразнее на основе приведенного ниже уравнения построить прямые в обратных координатах величин концентраций образовавшегося продукта $(P)$ и времени $(t)\left[{ }^{6}\right]$.

$$
\frac{1}{[P]_{t}}=\frac{1}{[P]_{\infty}}+\frac{1}{v_{0} t},
$$


где $v_{0}-$ начальная скорость и $[P]_{\infty}=[E]_{0} k_{2} / k_{i}$, так как

$$
[P]_{t}=[E]_{0} \frac{k_{2}}{k_{i}}\left(1-\mathrm{e}_{-k_{t} t}\right) \text {. }
$$

Уравнение (2) действительно при $[S]_{0} \gg K_{m}^{\text {каж }} \approx K_{s}$ и $\alpha \ll 1$. Для диоксигеназы величина $K_{m}^{\text {каж }}=5,5$ мкM определена по арахидоновой кислоте в ТРИС-буфере [ $\left.{ }^{4}\right]$, по кислороду значение этой константы не установ-

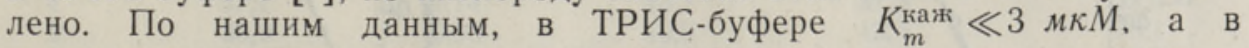
ЭДТА-буфере в несколько раз выше 3 мкМ.

Результаты расчета продукта реакции (по расходу 2 молей кислорода на 1 моль кислоты), образующегося в ходе окисления арахидоновой кислоты в обоих буферах, в предложенных координатах хорошо накладываются на прямую (рис. 1), за исключением точек при $t \ll 25$ c. Однако аналогичное явление можно отметить и в случае дан-

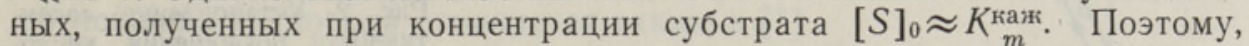
видимо, при изучении свойств диоксигеназы в виде нерастворимого ацетон-пентанового порошка все определяемые константы довольно формальны и по значениям $K_{m}^{\text {каж }}$ и $\alpha$ нельзя судить о применимости уравнения (2) к данному случаю. По полученной прямой легко определить значения $k_{i}$ и $k_{2}$. При небольшом значении [ $\left.S\right]_{0}$ происходит некоторое увеличение поглощения кислорода по сравнению с его стехиометрическим количеством, необходимым для полного окисления субстрата. При этом, как правило, значение $k_{i}$ несколько повышается. Думается, что это обусловлено окислением остаточных липидов, содержащихся в ацетон-пентановом порошке.

В начале реакции чаще всего наблюдается небольшая ляг-фаза. Поэтому, при учете также некоторой инерции измерительной системы, определение начальных скоростей весьма неточно и их лучше рассчитывать по уравнению (2).

Таблица 1

Результаты определения кинетических параметров биохимического окисления арахидоновой кислоты

\begin{tabular}{|c|c|c|c|c|}
\hline Условия определения & $\begin{array}{l}{[S]_{0}} \\
M \kappa M\end{array}$ & $\begin{array}{c}k_{i}, \\
M u H^{-1}\end{array}$ & $\begin{array}{c}k_{2}, \\
\dot{M U H}^{-1} \\
(\text { ноль/Mг) }\end{array}$ & $\begin{array}{l}P_{\infty}^{*} \\
\text { нмоль/M乙 }\end{array}$ \\
\hline ТРИС, $E \rightarrow S, \quad$ Е-1 & $\begin{array}{r}4,6 \\
9,1 \\
18,2 \\
36,4 \\
91,0 \\
182,0\end{array}$ & $\begin{array}{l}1,14 \\
1,08 \\
0,84 \\
0,51 \\
0,52 \\
0,46\end{array}$ & $\begin{array}{l}16,6 \\
21,8 \\
24,4 \\
22,6 \\
24,9 \\
24,6\end{array}$ & $\begin{array}{l}14,6 \\
20,2 \\
29,0 \\
44,3 \\
47,9 \\
53,5\end{array}$ \\
\hline ТРИС, $E \rightarrow S, \quad$ Е-2 & 28,3 & 0,78 & 45,4 & 58,2 \\
\hline ТРИС, $S \rightarrow E, \quad$ Е-2 & $\begin{array}{r}28,3 \\
56,6 \\
.182\end{array}$ & $\begin{array}{l}0,78 \\
0,78 \\
0,81\end{array}$ & $\begin{array}{l}68,4 \\
87,6 \\
68,4\end{array}$ & $\begin{array}{c}88,0 \\
112 \\
85,0\end{array}$ \\
\hline ЭДТА, $\quad E \rightarrow S, \quad$ Е-2 & $\begin{array}{l}56,6 \\
84,9 \\
113\end{array}$ & $\begin{array}{r}0,33 \\
0,45 \\
0,50\end{array}$ & $\begin{array}{l}21,8 \\
32,5 \\
28,5\end{array}$ & $\begin{array}{c}66,1 / 61,5^{* *} \\
72,2 \\
79,4\end{array}$ \\
\hline $\begin{array}{l}\text { ЭДТА, } E \rightarrow S, \quad \text { E-2 } \\
\text { кофакторы }\end{array}$ & 56,6 & 0,24 & 19,0 & $79,4 / 63,1^{* *}$ \\
\hline
\end{tabular}




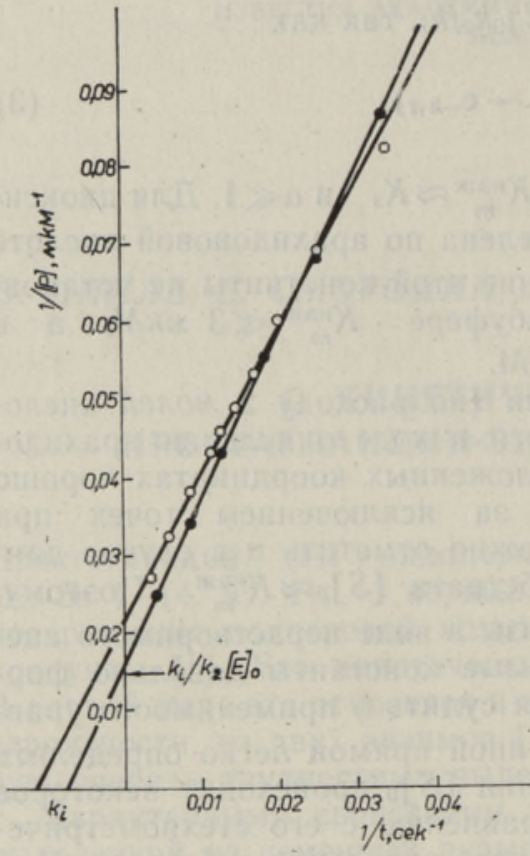

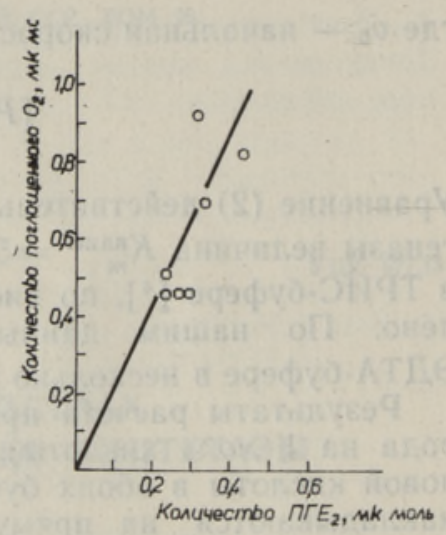

Рис. 2. Установление селективности поглощения кислорода для синтеза ПГЕ 2 .

Рис. 1. Пример определения значений $k_{i}$, $k_{2}$ и $v_{0}$ в ТРИС (О) и ЭДТА (2) буфере $\left([S]_{0}=80\right.$ мкM, $[E]_{0}=0,84$ мL/M $/$ ).

Попытки обработать данные поглощения кислорода в присутствии ПГ-синтетазы по схеме инактивации свободного энзима или независимо от субстрата дали менее удовлетворительные результаты. Принимая во внимание явление ляг-фазы, можно говорить о целесообразности использования общей кинетической схемы, предложенной в $\left[{ }^{4}\right]$.

Найденные значения $k_{i}$ в ТРИС-буфере приблизительно соответствуют величинам, определенным ранее $\left[{ }^{4}\right]$, однако значения каталитической константы для изученных синтетаз почти в 2-4 раза выше (табл. 1). Величина $k_{2}$ в значительной степени зависит от способа инициирования реакции: например, при инициировании энзимом она примерно на $50 \%$ выше, чем $k_{2}$, полученная при инициировании субстратом. Соответственно выше и максимальное количество продукта, полученного с единицы веса синтетазы $\left(P_{\infty}\right)$. При постепенном введении субстрата, а особенно энзима, количество поглощенного кислорода повышается еще на $10-20 \%$. Эти факты согласуются с тем, что начальная скорость поглощения кислорода зависит от последовательности добавления реагентов $\left.\left.\right|^{7}\right]$.

Следует отметить весьма высокую селективность образования конечного продукта ПГЕ 2 ряда последовательных реакций в ЭДТА-буфере (рис. 2).

В ЭДТА-буфере кривая поглощения кислорода имеет иной характер: значения $k_{i}$ и $k_{2}$ в данном случае значительно ниже, а $P_{\infty}$ выше соответствующих значений при применении ТРИС-буфера. Этот весьма любопытный, хорошо подтвержденный практикой препаративного синтеза факт объясняется молекулярными свойствами ЭДТА.

Добавление в ЭДТА-буфер кофакторов-глутатиона (GSH) и гидрохинона (HQ) еще больше снижает скорость инактивации и начальную скорость реакции с одновременным повышением суммарного количества продукта. Торможение реакции в препаративном биосинтезе ПГЕ ${ }_{2}$ объяснимо образованием обратимого ингибитора $\left[{ }^{8}\right]$. Однако в опытах 


\section{Таблица 2}

Результаты последовательного определения кинетических параметров без замены буфера (ТРИС, $E \rightarrow S$, Е-3, $[S]_{0}=28,3 \boldsymbol{м \kappa M}$ )

\begin{tabular}{|c|c|c|c|c|c|}
\hline $\begin{array}{c}\text { № } \\
\text { опыта }\end{array}$ & $\begin{array}{c}v_{0} \\
\text { нмоль } / \text { мин } \cdot \text { мг }\end{array}$ & $\begin{array}{c}k_{i} \\
M U H^{-1}\end{array}$ & $\begin{array}{c}k_{2} \\
\text { MUH }^{-1} \\
(\text { ноль } / \text { ML) }\end{array}$ & $\begin{array}{c}P_{\infty}, \\
\text { нМоль/Mг }\end{array}$ & $\begin{array}{c}P_{5}, \\
\text { нмоль } / \text { ма }\end{array}$ \\
\hline $\begin{array}{l}1 \\
2 \\
3 \\
4\end{array}$ & $\begin{array}{l}37,1 \\
38,9 \\
36,6 \\
36,6\end{array}$ & $\begin{array}{l}11,14 \\
0,96 \\
0,84 \\
0,84\end{array}$ & $\begin{array}{l}43,1 \\
40,8 \\
39,3 \\
39,3\end{array}$ & $\begin{array}{l}37,8 \\
42,5 \\
46,7 \\
46,7\end{array}$ & $\begin{array}{l}32,5 \\
36,1 \\
39,0 \\
43,3\end{array}$ \\
\hline
\end{tabular}

без замены буфера (табл. 2) никакого ингибирования не происходит. Заметна тенденция к уменьшению значения $k_{i}$. Тождественность кривых поглощения кислорода отмечается также в [ $\left.{ }^{9}\right]$.

Как и следовало ожидать, значения $v_{0}$, рассчитанные без учета лягфазы на ме синтетазы методом $\left[{ }^{10}\right]$, несколько ниже значений $k_{2}$.

При условии $k_{i} t \approx 5$ в уравнении (3) энзим полностью теряет активность. Однако значения $P_{\infty}$ в ТРИС-буфере на $20 \%$ выше значений $P_{5}$ (табл. 2). Такая же тенденция наблюдается в ЭДТА-буфере (табл, 1). Это показывает, что примененный метод подходит лишь для приблизительной оценки процесса биохимического окисления полиеновых кислот и возможность его применения окончательно может быть выяснена при изучении более чистых препаратов диоксигеназы. Пока же этот метод весьма полезен при оценке свойств ПГ-синтетазы, включая иммобилизованные синтетазы, в различных условиях.

\section{Экспериментальная часть}

Кинетические измерения потребления кислорода проводились при постоянной температуре реактора $30 \pm 0,02{ }^{\circ} \mathrm{C}$ с использованием кислородного электрода гальванического типа и самопишущей измерительной схемы с чувствительностью 1 нA/10 (соотношение времени запаздывания и постоянной времени $\ll 0,08$ ). Реакция инициировалась введением субстрата $(E \rightarrow S)$ или энзима $(S \rightarrow E)$ через боковую трубку реактора $\left([E]_{0}=0,84 \mathrm{Mz} / \mathrm{M}\right)$. Три партии ацетон-пентанового порошка (E-1 и т. д.) из семенных пузырьков барана $\left.{ }^{8}\right]$ подвергались гомогенизации в вакууме при $20^{\circ}$ в течение 0,5 ч в 0,1 М ТРИС- или 0,03 М ЭДТА-буфере, содержащих 0,07 мМ оксибензена (pH 8,5). В случае применения GSH и $\mathrm{HQ}$ их концентрации соответственно составляли 2 и 0,5 мМ. Субстрат выделялся из липидов по методике, разработанной в нашей лаборатории.

ПГЕ $E_{2}$ определялся по методу щелочной деградации $\left[{ }^{11}\right]$ с применением экспериментально установленного коэффициента экстинкции 22300 л/моль.см.

\section{Выводы}

1. Обработка данных кинетической кривой поглощения кислорода, полученных при окислении полиеновых кислот в присутствии ПГ-эндопероксид синтетазы, в обратных координатах величин концентрации образованного продукта и времени позволяет определить константу скорости первого порядка инактивации энзима $\left(k_{i}\right)$, каталитическую константу $\left(k_{2}\right)$ и максимальное количество продукта, получаемого с единицы веса энзима $\left(P_{\infty}\right)$, в применяемых условиях. 
2. Значения указанных констант зависят от типа буфера, кофакторов и способа инициирования реакции.

3. В применяемых условиях при биосинтезе ПГЕ 2 образования обратимого ингибитора не наблюдается.

\section{Л И ТЕ Р А Т У Р А}

1. Hemler, M., Lands, W. E. M., S m ith, W. L. Purification of the cyclooxygenase that forms prostaglandins. - J. Biol. Chem., 1976, v. 251, N 12, p. $5575-5579$.

2. Hemler, M. E., Lands, W. E. M. Biosynthesis of prostaglandins. - Lipids, 1977 , v. 12, N 7, p. $591-595$.

3. Rome, L. H., Lands, W. E. M. Properties of a partially-purified preparation of the prostaglandin-forming oxygenase from vesicular gland. - Prostaglandins, 1975 , v. 10 , N 5 , p. $813-824$.

4. S m ith, W. L., Lands, W. E. M. Oxygenation of polyunsaturated fatty acids during prostaglandin biosynthesis by sheep vesicular gland. - Biochem., 1972, v. $11, \mathrm{~N} 17$, p. $3276-3285$.

5. Cook, H. W., La nd s, W. E. M. Evidence for an activating factor formed during prostaglandin biosynthesis. - Biochem. Biophys. Res. Commun., 1975, v. 65, N 2, p. $464-471$.

6. Roy, A. B. Kinetic properties of arylsulphatase $A$ - theoretical treatment. Biochim. Biophys. Acta, 1972 , v. 276 , p. $475-490$.

7. Yoshimoto, A., Ito, H., Tomita, K. Cofactor requirements of the enzyme synthesizing prostaglandin in bovine seminal vesicles. - J. Biochem., 1970, v. $4, \mathrm{~N} 68$, p. $487-499$.

8. Wa li a ch, D. P., D a n i els, E. G. Properties of a novel preparation of prostaglandin synthetase from sheep seminal vesicles. - Biochim. Biophys. Acta, 1971 , v. 231 , p. $445-457$.

9. E g a n, R. W., P a x t o n, I., Ku eh l, F. A. Mechanism for irreversible self deactivation of prostaglandin synthetase. - J. Biol. Chem., 1976, v. 251, N 23, p. $7329-7335$.

10. С и й м е р Э. Х., П аппель К. Э., Кёстн ер А. И. Новый метод описания кинетики ферментативных́ реакций. - Тр. Таллин. политех. ин-та, 1977, № 427, c. $13-17$.

11. B y g d e ma n, M., S a m ue $1 \mathrm{~s}$ o n, B. Quantitative determination of prostaglandins in human semen. - Clin. Chim. Acta, 1964, v. 10, p. 566-568.

$\begin{array}{cc}\text { Институт химии } & \text { Поступила в редакцию } \\ \text { Академив наук Эстонской ССР } & 26 / \mathrm{X} \\ 1978\end{array}$

O. LILLE, J. SMORODIN, R. MARVET

\section{PROSTAGLANDIINENDOPEROKSIIDSUNTETAASI KINEETILISTEST OMADUSTEST}

Hapniku neeldumiskõvera töötlemisel arahidoonhappe oksüdatsiooni produkti kontsentratsiooni ja oksüdatsiooni aja pöördkoordinaatides on võimalik ühest katsest määrata süntetaasi kineetilised omadused. On käsitletud viimaste sõltuvust puhvri tüübist, kofaktoreist ja reaktsiooni initsieerimise viisist.

\section{ON KINETIC PROPERTIES OF PROSTAGLANDIN-ENDOPEROXIDE SYNTHETASE}

The first order inactivation rate constant of acetone-pentane powder, catalytical constant and maximal quantity of oxydation product formed from arachidonic acid, were calculated by making use of reversed coordinates of product concentration and oxydation time. The dependence of these parameters on type of buffer and initiation of reaction is discussed. 